\title{
Conservative approach versus urgent appendectomy in surgical management of acute appendicitis with abscess or phlegmon
}

\author{
J. M. Aranda-Narváez, A. J. González-Sánchez, N. Marín-Camero, C. Montiel-Casado, P. López-Ruiz, \\ B. Sánchez-Pérez, A. Álvarez-Alcalde, C. P. Ramírez-Plaza and J. Santoyo-Santoyo \\ Servicio de Cirugía General, Digestiva y Trasplante. Hospital Regional Universitario Carlos Haya. Málaga, Spain
}

\begin{abstract}
Background: Surgical management of acute appendicitis with appendiceal abscess or phlegmon remains controversial. We studied the results of initial conservative treatment (antibiotics and percutaneous drainage if necessary, with or without interval appendectomy) compared with immediate surgery.

Methods: We undertook an observational, retrospective cohort study of patients with a clinical and radiological diagnosis of acute appendicitis with an abscess or phlegmon, treated in our hospital between January 1997 and March 2009. Patients younger than 14 , with severe sepsis or with diffuse peritonitis were excluded. A study group of 15 patients with acute appendicitis complicated with an abscess or phlegmon underwent conservative treatment. A control group was composed of the other patients, who all underwent urgent appendectomy, matched for age and later randomized 1:1. The infectious risk stratification was established with the National Nosocomial Infections Surveillance System (NNIS) index. Dependent variables were hospital stay and surgical site infection. Analysis was with SPSS, with $\mathrm{p}<0.05$ considered significant.

Results: Interval appendectomy was performed in 7 study group patients. Surgical site infection episodes were more frequent in the control group ( 6 vs. $0, p<0.001)$. A greater percentage of high risk patients (NNIS $\geq 2$ ) was identified in the control group (80 vs. $28.7 \%, p<0.03$ ), mostly related with contaminated or dirty procedures in this group $(p<0.001)$. No significant difference between groups was found in hospital stay.

Conclusion: Initial conservative treatment should be considered the best therapeutic choice for acute appendicitis with abscess or phlegmon.
\end{abstract}

Key words: Acute appendicitis. Appendiceal abscess. Appendiceal phlegmon. Interval appendectomy. Laparoscopy.

Recceived: $30-04-10$

Accepted: $12-05-10$

Correspondence: José Manuel Aranda-Narváez. Secretaría del Servicio de Cirugía General, Digestiva y Trasplante. Hospital Regional Universitario Carlos Haya. Avda. Carlos Haya, s/n. 29010 Malaga, Spain. e-mail: josearanda68@telefonica.net

\section{RESUMEN}

Introducción: Existe controversia acerca del tratamiento idóneo de la apendicitis aguda evolucionada en forma de absceso o flemón. Realizamos un estudio para la evaluación de resultados del tratamiento conservador inicial (antibiótico y drenaje percutáneo si se precisa, con/sin apendicectomía diferida) y del tratamiento quirúrgico urgente.

Método: Estudio observacional analítico de cohortes retrospectivas. Criterios de inclusión: pacientes con diagnóstico clínico y radiológico de apendicitis aguda evolucionada en forma de absceso o flemón, tratados en nuestro hospital entre enero 1997 y marzo 2009, excluyendo pacientes pediátricos, con sepsis grave o peritonitis difusa. En 15 pacientes con apendicitis complicada con absceso o flemón (cohorte de estudio) se indicó tratamiento conservador inicial. El grupo control se obtuvo del resto de pacientes (en todos ellos se indicó apendicectomía urgente) mediante un matching por edad y asignación aleatoria posterior (1:1). La estratificación del riesgo infeccioso se determinó mediante el índice National Nosocomial Infections Surveillance System (NNIS). Variables resultado: estancia global e infección de sitio quirúrgico. Se consideraron de relevancia estadística niveles de significación $<0,05$.

Resultados: En 7 pacientes del grupo de estudio se indicó apendicectomía diferida. La incidencia de episodios de infección de sitio quirúrgico fue significativamente mayor en el grupo control $(6$ vs. $0, p<0,001)$. Un mayor porcentaje de pacientes con NNIS de alto riesgo $(\geq 2)$ se objetivó en el grupo control $(80 \%$ vs. $28,7 \%, p<0,03)$. El item determinante fue el carácter contaminado o sucio de las apendicectomías urgentes ( $p<0,001)$. La estancia global no mostró diferencias significativas entre grupos.

Conclusión: El tratamiento conservador inicial constituye la mejor alternativa terapéutica para la apendicitis aguda evolucionada.

Palabras clave: Apendicitis aguda. Absceso apendicular. Flemón apendicular. Apendicectomía diferida. Laparoscopia.

Aranda-Narváez JM, González-Sánchez AJ, Marín-Camero N, Montiel-Casado C, López-Ruiz P, Sánchez-Pérez B, Álvarez-Alcalde A, Ramírez-Plaza CP, Santoyo-Santoyo J. Conservative approach versus urgent appendectomy in surgical management of acute appendicitis with abscess or phlegmon . Rev Esp Enferm Dig 2010; 102: 648-652. 


\section{INTRODUCTION}

Acute appendicitis is still the most frequent cause of acute abdomen in young patients. Its peak incidence occurs in the $20 \mathrm{~s}$ and $30 \mathrm{~s}$, and there is a slight predominance of men over women. Despite its simple clinical diagnosis, with or without the use of scores (1), radiological advances and the possibility of a laparoscopic approach, 20-30\% of cases of appendicitis are reported to be gangrenous or perforated, due to delays either in requesting help or in the diagnosis itself, with the resulting increase in associated morbidity and mortality (2). Additionally, in relation to subclinical presentation and especially in older patients, up to $10 \%$ of patients are diagnosed with an appendiceal mass $(3,4)$. Numerous studies have supported an initial conservative therapeutic approach with antibiotics for acute appendicitis with a late onset in the form of an abscess or phlegmon, together with percutaneous drainage if required. Nonetheless, evidence also exists for an urgent surgical approach of this condition in terms of safety and cost-effectiveness. In the absence of randomized, controlled, prospective trials, no clear indication is available concerning the optimal therapeutic decision for these patients. We present a study undertaken at a third-level university hospital to evaluate the two types of treatment.

\section{AIM}

To evaluate the results of treatment of acute appendicitis with appendiceal abscess or phlegmon: initial conservative treatment (antibiotics and percutaneous drainage if required) with or without deferred appendectomy vs. urgent surgical treatment.

\section{MATERIAL AND METHODS}

We undertook an analytical observational study of retrospective cohorts. The patients, all of whom had a clinical and radiological (echography and/or computerized tomography) diagnosis of acute appendicitis with appendiceal abscess or phlegmon, were treated at "Carlos Haya" Regional University Hospital, Malaga, Spain (third level) between January 1997 and March 2009. Patients were excluded: a) if they were pediatric patients (treated elsewhere); b) had severe sepsis, defined according to the criteria of consensus documents on intra-abdominal infection (two or more criteria of systemic inflammatory response syndrome -SIRS- with organ failure). Sepsis in the absence of criteria of severity (SIRS associated with a focus of infection) was not considered to be an exclusion criterion (5); and c) initial clinical, radiological or intraoperative evidence of diffuse peritonitis. These criteria were fulfilled by 15 patients, who comprised the study group and in whom initial con- servative antibiotic treatment was indicated, with or without percutaneous drainage of periappendicular abscesses (Fig. 1), indicating deferred appendectomy depending on their posterior course. The admitting physician established the indication. A control group was formed of the other patients who fulfilled the inclusion criteria and who underwent urgent appendectomy. These patients were age-matched with each of the study group patients and

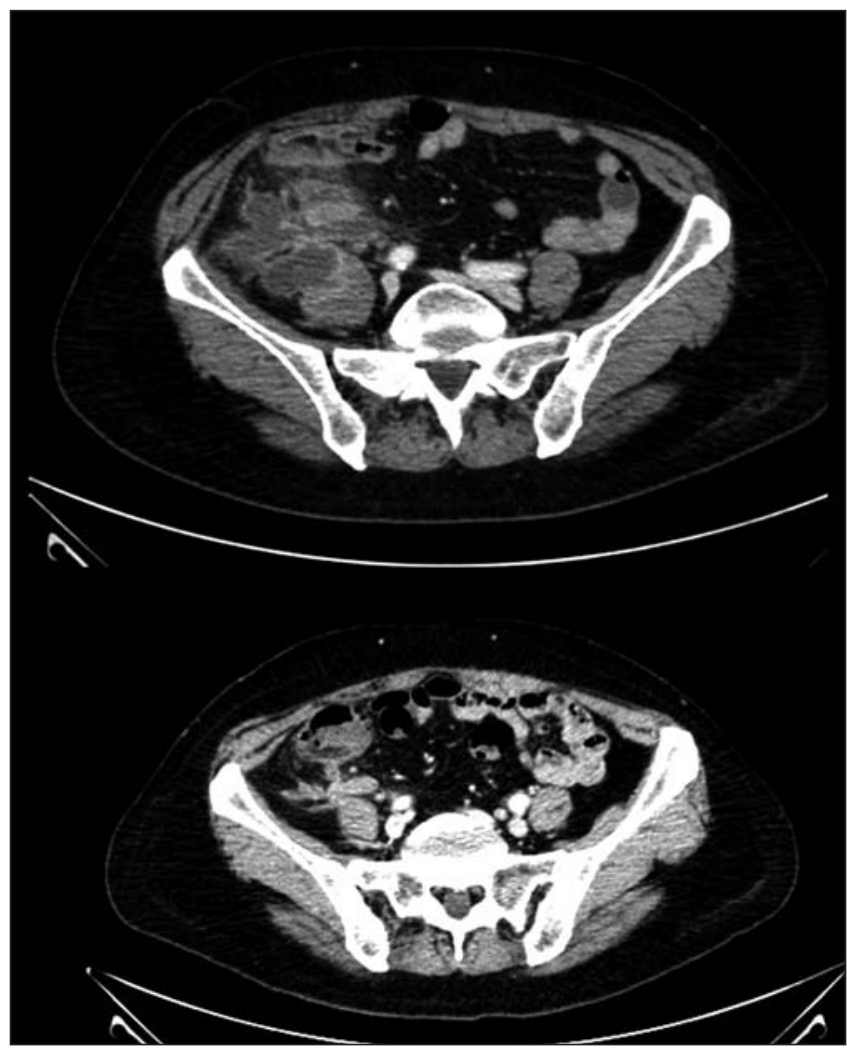

Fig. 1. Resolutive capacity of conservative treatment. Appendicular abscess (top): percutaneous drainage and antibiotic therapy. Control at 10 days (bottom): frank radiological improvement, with the caecal appendix visible.

then selected randomly one to one. In both groups the main surgeon decided on the type of approach for the appendectomy (open or laparoscopic). The main predictive variable was the type of treatment (initial conservative vs. urgent appendectomy). The infectious risk stratification was determined using the National Nosocomial Infections Surveillance System (NNIS index) (6), which defines a score of 0-3 considering the anesthesia risk according to the American Society of Anesthesiologists (ASA), the surgical time (specifically defined for each surgical procedure by the Centers for Diseases Control and Prevention -CDC- and established as one hour for an appendectomy) and the classification of the type of surgery according to the National Research Council 
(NRC). One point is subtracted from the resulting value in the event of a laparoscopic approach. An overall and individual analysis was done of the component items of the score to determine the intergroup variability. The resulting variables were overall stay (including a second admission for the study group patients in the event of deferred appendectomy) and associated morbidity, centered mainly on surgical site infection (SSI), defined according to the CDC standards (7), with individual follow-up at 30 days to detect any infectious episodes after hospital discharge.

\section{Statistical analysis}

Statistical analysis was done with the Statistical Package for Social Sciences (SPSS), applying the $\chi^{2}$ test (with Yates correction and Fisher's exact test) and the Student t or Mann Whitney U tests according to the characteristics of the study variables and the conditions of applicability. Statistical significance was set at $\mathrm{p}<0.05$.

\section{RESULTS}

The median age of both groups was 35 years. In addition to this variable (which was used for the matching), both groups were similar with respect to gender, progression time, ASA anesthesia risk index and the presence of sepsis (Table I). No patient died in relation with the episode in either group.

Table I. Group homogeneity

\begin{tabular}{|c|c|c|c|}
\hline & & $\begin{array}{c}\text { Study Group } \\
\text { (initial conservative } \\
\text { treatment) }\end{array}$ & $\begin{array}{l}\text { Control Group } \\
\text { (initial surgical } \\
\text { treatment) }\end{array}$ \\
\hline Age $(y$ & & $35.4(r: 15-63)$ & 35.8 (r: 16-64) \\
\hline Gende & & $8 / 7$ & $11 / 4$ \\
\hline \multicolumn{4}{|c|}{ Progression time } \\
\hline \multirow[t]{3}{*}{ ASA } & I & 4 & 5 \\
\hline & $\|$ & 3 & 9 \\
\hline & III & 0 & 1 \\
\hline \multicolumn{2}{|c|}{ Sepsis (yes/no) } & $3 / 12$ & $5 / 10$ \\
\hline
\end{tabular}

Table II shows the results concerning events related with treatment selection, morbidity and overall stay. The median stay for the study group patients was 10 days (range, 4-18) for parenteral antibiotic therapy. Seven patients $(46.6 \%)$ had a periappendicular abscess, with a sufficient clinical entity and accessibility to perform percutaneous drainage in all cases. The initial conservative treatment was successful in all cases, with none requiring urgent surgery during the first admission. Later, seven pa-

\begin{tabular}{llccc}
\multicolumn{5}{c}{ Table II. Events related with treatment. Morbidity and } \\
overall stay
\end{tabular}

*PC: potentially contaminated; C or D: contaminated or dirty.

tients $(46.6 \%)$ underwent deferred appendectomy. In five of these the indication was based on symptomatic recurrence (33.3\% of the overall study group), in the form of episodes of right iliac fossa pain and self-limiting fever reported during the office follow-up visit. These episodes constituted the reason for readmission in two patients, with radiological diagnosis of a relapse of the appendicular inflammatory process requiring appendectomy during the readmission, although following a further antibiotic schedule. One patient was diagnosed with adenocarcinoma of the cecum by colonoscopy during the office follow-up visit; this patient underwent an elective right oncological hemicholectomy one month after the first admission. The last of these seven patients required an elective appendectomy due to the radiological presence of an intraluminal fecalith. No relation was seen between the initial type of presentation (abscess or phlegmon) and the need for deferred appendectomy $(p<0.4)$. The median interval between the first admission and the elective appendectomy was 12 weeks (range, 4-36), and this was done via laparoscopy in three patients $(42.9 \%)$. None of the study group patients had SSI.

In the control group the presence of a periappendicular abscess was detected intraoperatively in nine patients $(60 \%)$. The laparoscopic approach was only completed on two occasions (13.3\%). The SSI percentage in the control group after the initial urgent appendectomy was 40\% (6 episodes: 3 superficial, 2 deep, 1 organ/space).

The stratification of the infectious risk according to the NNIS index showed a clear superiority in the per- 
centage of patients with a high-risk NNIS $(\geq 2)$ in the control group as compared with the study group (80 vs. $28.6 \%, \mathrm{p}<0.03)$. The individual analysis of the component items showed no significant differences between the groups in relation to the ASA $(\mathrm{p}<0.5)$ or the surgical time $(\mathrm{p}<0.91)$. However, a clear difference was found concerning the type of procedure according to the NRC classification: surgery with a contaminated or dirty character was established in all the control group appendectomies but in only two of the seven surgical procedures carried out in the study group, with a clear statistical association $(\mathrm{p}<0.001)$.

The overall stay (including the stay related with the deferred appendectomy in the study group) showed no significant differences between the two groups ( $p<0.16$, n.s.).

\section{DISCUSSION}

The paucity of evidence explains the continuity of the debate about the ideal therapeutic approach for acute complicated appendicitis $(4,8)$. The main arguments against an initial conservative approach are based on the potential recurrence of symptoms and consequent readmission with an increased overall hospital stay, in the chance to rule out any underlying malignant disorder and that an immediate surgical solution proves definitive, as well as being safe and cost-effective, and is also possible by a laparoscopic approach.

Numerous studies have shown that recurrence after conservative treatment in patients with an appendicular mass is low $(9,10)$ and that the need for deferred appendectomy should not be generalized, just being indicated according to disease progression. In our study, however, the rate of recurrence of symptoms after initial conservative treatment was higher. This finding, from a small sample of patients, should not be interpreted as indicative of the need for systematic deferred appendectomy but rather as an indication for the follow-up and monitoring of patients with conservative treatment after hospital discharge. The findings of our study do, however, suggest the need to prioritize the programming of deferred appendectomy in indicated patients (symptomatic recurrence) as a measure to avoid further inflammatory attacks.

The presence of associated malignancy is unusual, with systematic reviews suggesting a figure of around $1.2 \%$ (8) and patients above the age of 40 years being more at risk (4). Other disorders, like those grouped under the clinical concept of appendicular mucocele, are equally exceptional (11) The inflammatory presentation of appendicular neoplastic disease was also clearly reflected in our study. Fulfilling the premises of a strict diagnostic battery in at-risk patients, this disease is detectable and opportune treatment can be started within established periods without affecting patient safety.

The most notable difference between the two types of treatment concerned morbidity in the form of postappendectomy SSI. In our study, the postoperative SSI figures associated with urgent appendectomy as the initial treatment (control group) were much greater than those of elective appendectomy after conservative antibiotic therapy. According to the evidence, the percentage of clinical and radiological success of conservative treatment is high (a failure rate of around 7.2\%) whereas morbidity associated with an initial surgical approach is three times greater (8), mainly in relation to the SSI. The predictive capacity of SSI risk of the NNIS index is even more evident, by qualifying a higher percentage of patients with a high risk for infection in the control group, and doing it with the score component related with the type of surgery according to the NRC classification. The intraoperative findings in those cases of urgent surgery for complicated acute appendicitis often correspond with the conditioning factors for future infection. The presence of periappendicular abscess in $60 \%$ of the patients who underwent urgent surgery ratifies this qualification. A simple reading consists of stating that with initial conservative treatment of acute complicated appendicitis the percentage of postappendectomy SSI is lower, as it converts an urgent appendectomy (which ensures the contaminated or dirty nature of the operation) into a possible deferred appendectomy that more often becomes a potentially contaminated surgery, independently of the choice of an open or laparoscopic approach.

Though not really the focus of the study, two questions arise concerning the applicability and advantages and disadvantages of laparoscopy for acute complicated appendicitis, both for deferred appendectomy (after initial conservative treatment, if indicated) and for urgent appendectomy. The former concerns whether initial conservative management results in greater applicability of the laparoscopic approach for appendectomy. Whilst our data suggest this to be the case, the result should be considered with caution given the progressive confirmation of the resolutionary potential of laparoscopy in all types of appendectomies, even those performed in complicated cases $(4,12)$. The differences noted in our study are related with the small samples and a long recruitment period, with the progressive incorporation of the laparoscopic approach to the therapeutic arsenal, such that the differences between the two groups in terms of surgical approach may well no longer exist. We accept that there are interfering limitations despite the results.

A further question, closer to the centre of the study, is whether the generalization and diffusion of the laparoscopic approach will contribute to the control of the high figures of SSI reported for urgent appendectomy due to acute complicated appendicitis. If this proves to be the case, urgent appendectomy via laparoscopy will become the gold standard for treatment of this disease, possibly even to the detriment of initial conservative treatment. Systematic reviews, like those of Sauerland (13) or Bennett (14), suggest an increase in organ/space infections 
with laparoscopy for appendectomy, particularly in advanced stages of inflammatory appendicular disease. Recent series have confirmed the persistence of this problem associated with laparoscopic appendectomy $(15,16)$. Thus, although a laparoscopic approach reduces the rates of parietal infection (superficial and deep), the overall rates of SSI obtained with the open and the laparoscopic approaches (always within the clinical context of acute complicated appendicitis) will become similar at the expense of a greater number of organ/space infections (which have more important repercussions and intrinsic therapeutic difficulty) associated with the latter, which would be an excessive price to pay. Whatever the case, further studies are required to specifically examine this question.

Finally, in relation to hospital stay, even considering the stay related with deferred appendectomy in the study group, we found no significant differences between the two therapeutic approaches. The homogeneity of the hospital stay is related with the fact that, although an initial conservative management may mean the need for readmission for a further inflammatory attack or for an elective appendectomy, an urgent and immediate appendectomy is associated with a high rate of postoperative SSI, which lengthens the stay for therapeutic reasons. Thus, there does not appear to be a clear difference in overall hospitalization concerning an initial conservative approach for acute complicated appendicitis.

In the absence of prospective studies with large series of patients, and given the difficulty of randomization when assigning treatment, the only evidence available comes from reviews and meta-analyses of retrospective studies with small series $(4,8)$. Accordingly, not enough evidence is yet available to determine the optimal treatment of acute complicated appendicitis. In view of the findings of this study and other available data, conservative treatment can be considered safe, with a low rate of symptomatic recurrence, with a minimal associated incidence of neoplastic disorders that are easily detectable. The correct selection of patients (absence of peritonitis or severe sepsis) is of course a sine qua non condition for the success of this therapeutic approach. Morbidity (particularly in the form of SSI) associated with urgent appendectomy is not negligible and it is greater than that associated with conservative treatment and deferred appendectomy. The relevant data suggest that generalization of the laparoscopic approach will not contribute to homogenize the rates of SSI between the two types of treatment, though confirmatory studies are necessary. It would therefore seem prudent to recommend conservative antibiotic therapy, with or without percutaneous drainage, as the choice for acute complicated appendicitis with an abscess or phlegmon, with deferred appendectomy being reserved for cases of symptomatic persistence or recurrence.

\section{REFERENCES}

1. Navarro-Fernández JA, Tárraga-López PJ, Rodríguez-Montes JA, López-Cara MA. Validity of tests performed to diagnose acute abdominal pain in patients admitted at an emergency department. Rev Esp Enferm Dig 2009; 101 (9): 610-8.

2. Granero-Castro P, Raposo-Rodríguez L, Moreno-Gijón M, PrietoFernández A, Granero-Trancón J, González-González JJ, et al. Pylephlebitis as a complication of acute apendicitis. Rev Esp Enferm Dig 2010; 102 (3): 217-22.

3. Prytowsky JB, Pugh CM, Nagle AP. Appendicitis. Curr Probl Surg 2005; 42: 694-742.

4. Meshikhes AW. Management of appendiceal mass: controversial issues revisited. J Gastrointest Surg 2008; 12 (4): 767-75.

5. Guirao X, Arias J, Badía JM, García-Rodriguez JA, Mensa J, A1varez-Lerma F, et al. Recomendaciones en el tratamiento antibiótico empírico de la infección intraabdominal. Rev Esp Quimioter 2009; 22 (3): 151-72.

6. Culver DH, Horan TC, Gaynes RP, Martone WJ, Jarvis WR, Emori TG, et al. Surgical wound infection rates by wound class, operative procedure, and patient risk index. National Nosocomial Infections Surveillance System. Am J Med 1991; 91(Supl 3B): 152S-7S.

7. Mangran AJ, Horan TC, Pearson ML, Silver LC, Harvis WR; The Hospital Infection Control Practices Advisory Committee. Guideline for prevention of surgical site infection, 1999. Centers for Disease Control and Prevention (CDC) Hospital Infection Control Practices Advisory Committee. Am J Infect Control 1999; 27 (2): 97-132.

8. Andersson RE, Petzold MG. Nonsurgical treatment of appendiceal abscess or phlegmon: a systematic review and meta-analysis. Ann Surg 2007; 246 (5): 741-8.

9. Deakin DE, Ahmed I. Interval appendicectomy after resolution of adult inflammatory appendix mass: is it necessary? Surgeon 2007; 5 (1): 45-50.

10. Tekin A, Kurtoglu HC, Can I, Oztan S. Routine interval appendectomy is unnecessary after conservative treatment of appendiceal mass. Colorectal Dis 2008; 10 (5): 465-8.

11. Utrillas-Martínez AC, Muniesa-Soriano JA, del Val-Gil JM, CrucesConde A, López-Peris P, González-Penabad M, et al. Appendicular mucocele. Rev Esp Enferm Dig 2008; 100 (11): 730-8.

12. Senapathi PS, Bhattacharya D, Ammori BJ. Early laparoscopic appendectomy for appendicular mass. Surg Endos 2002; 16 (12): 1783-5.

13. Sauerland S, Lefering R, Neugebauer EAM. Laparoscopic versus open surgery for suspected appendicitis. Cochrane Database of Systematic Reviews 2004, Issue 4. Art. No.: CD001546. DOI: 10.1002/14651858.CD001546.pub2.

14. Bennett J, Boddy A, Rhodes M. Choice of approach for appendicectomy: a meta-analysis of open versus laparoscopic appendicectomy. Surg Laparosc Endosc Percutan Tech 2007; 17 (4): 245-55.

15. Kehagias I, Karamanakos SN, Panagiotopoulos S, Panagopoulos K, Kalfarentzos F. Laparoscopic versus open appendectomy: which way to go? World J Gastroenterol 2008; 14 (31): 4909-14.

16. Pokala N, Sadhasivam S, Kiran RP, Parithivel V. Complicated appendicitis: is the laparoscopic approach appropriate? A comparative study with the open approach: outcome in a community hospital setting. Am Surg 2007; 73 (8): 737-41; discussion 741-2. 